\title{
Short Communication \\ Second primary cancers in patients with skin cancer: a population-based study in Northern Ireland
}

\author{
MM Cantwell', , LJ Murray', D Catney², D Donnelly², P Autier ${ }^{3}$, M Boniol $^{3}$, C Fox $^{2}$, RJ Middleton ${ }^{2}$, OM Dolan $^{4}$ \\ and AT Gavin ${ }^{2}$ \\ 'Cancer Epidemiology and Prevention Research Group, Centre for Clinical and Population Sciences, Queen's University Belfast, Belfast, Northern Ireland; \\ ${ }^{2}$ Queen's University Belfast, Northern Ireland Cancer Registry, Royal Victoria Hospital, Belfast, Northern Ireland; ${ }^{3}$ Epidemiology Methods and Support \\ group, International Agency for Research on Cancer, Lyon, France; ${ }^{4}$ Department of Dermatology, Royal Victoria Hospital, Belfast, Northern Ireland
}

Melanoma and non-melanoma skin cancers (NMSC) (basal cell carcinoma (BCC) and squamous cell cancer (SCC)) show an increasing incidence worldwide (Jemal et al, 2001), including Northern Ireland (Hoey et al, 2007). There are limited epidemiological data concerning whether individuals with skin cancer are at an elevated risk of developing other malignancies. Tuohimaa et al (2007) combined data from 13 cancer registries and found 23 and $39 \%$ increased risks of several second primary cancers after a melanoma or NMSC, respectively. Decreases in risk of prostate (De Vries et al, 2007) and colorectal cancer (Soerjomataram et al, 2008) have been reported following a skin cancer, whereas a recent meta-analysis showed a significant reduction in colon cancer among patients with previous SCC (Grant, 2007).

We investigated the subsequent risk for any cancer in patients with BCC, SCC or melanoma. We also examined the reciprocal association for subsequent skin cancer after a primary colorectal cancer (as a validation exercise), as we hypothesised that patients with colorectal cancer, a cancer related to low vitamin D levels (Gorham et al, 2007), would have had a lower lifetime exposure to the sun and therefore have a lower risk of a subsequent skin cancer.

\section{MATERIALS AND METHODS}

The Northern Ireland Cancer Registry (NICR) is a populationbased registry that receives data routinely from 13 hospital administration systems, five pathology laboratories and eight radiology sites. It holds complete data on all neoplasms diagnosed within the province since the beginning of 1993. In addition,

* Correspondence: Dr MM Cantwell, Centre for Clinical and Population Sciences, Queen's University Belfast, Mulhouse Building, Royal Victoria Hospital Site, Grosvenor Road, Belfast BTI2 6BJ, Northern Ireland; E-mail: m.cantwell@qub.ac.uk

Received 10 September 2008; revised 21 November 2008; accepted 28 November 2008 a partially complete database of tumours diagnosed between 1989 and 1992 is also held by the NICR. Patients with pathologically confirmed NMSC are registered according to the European Network of Cancer Registries' guidelines for NMSC (Davies et al, 2007), which recommend that only the first occurrence of NMSC is registered based upon date of diagnosis and histological type (BCC or SCC). The latter is quality assured by NICR using all available information (such as primary site, patient history and general knowledge of tumour biology). Version 10 of the International Classification of Diseases was used to identify NICR registrations of NMSC (C44) and malignant melanoma (C43). Non-melanoma skin cancer cases registered with SNOMED codes between 80903 and 80953 were considered as BCC whereas those with SNOMED code 80703 or 80713 were considered SCC. Other types of NMSC were excluded from the analysis (1183 patients) due to the variety of histological types in the small number of patients.

In addition, the 1989-1992 database was used to eliminate from the 1993-2002 cohorts patients diagnosed with NMSC or melanoma during 1989-1992. A further 58 BCC, four SCC and two melanoma patients were also excluded as they were either diagnosed outside Northern Ireland (and could therefore not be followed for subsequent cancer risk) or were 100 years old or more when diagnosed. In total, 1837 melanoma, 6401 SCC and 14442 BCC patients were followed up to 31 December 2002 for a second primary neoplasm or death, the latter through linkage to death records held by the Registrar General's Office (GRO), Northern Ireland.

The outcome measures were classified according to ICD 10 as follows:

Any malignant neoplasm C00-C97; melanoma C43; SCC C44; BCC C44; lung C33 and C34; breast (female only) C50; cervix C53; uterus C54; ovary C56; prostate C61; oesophagus and stomach $\mathrm{C} 15$ and $\mathrm{C} 16$; colorectal $\mathrm{C} 18-\mathrm{C} 21$; haematological malignancies C81-C96; and non-Hodgkin's lymphoma C82-C85. Tobaccorelated cancers were also grouped as one outcome variable and included ICD 10 codes C00-C16, C22, C25, C32-34, C53, C64-C68 and C92. 


\section{Statistical analysis}

Observed numbers of cancers and person-years at risk were calculated by sex and 5-year age group. Expected numbers of cancers were obtained by multiplying the age-specific numbers of person-years with the corresponding cancer incidence rates in Northern Ireland, adjusting for gender for the overall standardised incidence ratios (SIRs). Exact 95\% confidence intervals (CIs) were calculated, assuming that the numbers of observed cases followed a Poisson distribution (Breslow and Day, 1987).

\section{RESULTS}

The absolute incidence of BCC was 86.6 cases per 100000 personyears and the mean (s.d.) age at diagnosis was 66.7 (s.d. 12.9) years in men and 69.0 (s.d. 13.9) in women. Compared with the general population, overall, the BCC patients had a $9 \%$ increased incidence of new primary cancers, more than a two-fold increased risk of subsequent melanoma and $14 \%$ increased risk of SCC (Table 1).

The absolute incidence of SCC was 38.4 cases per 100000 person-years and the mean (s.d.) age at diagnosis was 72.4 (11.4) years in men and 76.1 (12.0) years in women. In SCC patients, new primaries at any site were increased by more than $50 \%$ and the BCC incidence by more than two-fold (Table 2). Melanoma incidence was three times higher in men but not higher in women with an SCC and subsequent tobacco-related cancers were more likely in both sexes. Women with an SCC were less likely to have a subsequent breast cancer.

The absolute incidence of melanoma was 11.0 cases per 100000 person-years. The mean (s.d.) age at diagnosis was 56.6 (18.3) years in men and 55.4 (20.3) years in women. Melanoma was followed by an increased risk of any subsequent cancer $(\mathrm{SIR}=2.06 ; 95 \%$ CI $1.73-2.39)$, melanoma $(\mathrm{SIR}=4.79 ; 95 \% \mathrm{CI}$ 1.24-8.34), BCC $(\operatorname{SIR}=4.95 ; 95 \%$ CI 3.78-6.12) and SCC $(\mathrm{SIR}=2.50 ; 95 \%$ CI $1.24-3.77)$.

During the study period, the 9144 individuals registered with colorectal cancer showed, in contrast to our hypothesis, an increased risk of a second cancer $(\operatorname{SIR}=1.31 ; 95 \%$ CI $1.20-1.42)$ and an increased risk of BCC (SIR $=1.36 ; 95 \%$ CI $1.11-1.61)$, a sun-related cancer. In addition, their subsequent risk of developing other cancers related to low vitamin $\mathrm{D}$ levels, such as prostate and breast cancer, was not increased (SIR $=0.97 ; 95 \%$ CI $0.66-1.28$ and SIR $=0.89 ; 95 \%$ CI $0.55-1.23$, respectively).

\section{DISCUSSION}

Our population-based study included all incident cases of BCC (14 422), SCC (6401) and melanoma (1837) reported to the Northern Ireland Cancer Registry between 1993 and 2002. Compared with the general population, the incidence of new primaries after BCC or SCC was increased by 9 and $57 \%$, respectively. However, the subsequent risk of any cancer was more than double after melanoma.

Using NMSC, as a surrogate measure of long-term sun exposure, has suggested that exposure is associated with a lower risk of prostate cancer (de Vries et al, 2007). Our findings do not agree, and men with a BCC, SCC or melanoma did not have a decreased prostate cancer risk. An appreciable body of evidence suggests that the beneficial effect of continuous sun exposure on colorectal cancer risk is mediated through effects on the metabolism of vitamin $\mathrm{D}$, as this can suppress cell proliferation, cancer development and metastasis (Gorham et al, 2007). We therefore hypothesised that colorectal cancer would be associated with a lower risk of other sun-related cancers (skin cancer) and a higher risk of developing cancers related to low vitamin D levels. In contrast, we found that they had an increased risk of a subsequent BCC and that their subsequent risk of prostate and breast cancer was not increased. Our results agree with those of Tuohimaa et al (2007), who reported that NMSC is only protective against subsequent solid cancers in sunny countries, which perhaps indicates a less variable vitamin $\mathrm{D}$ exposure and in turn less variable vitamin $\mathrm{D}$ status than in Northern, less sunny countries. In such countries, as Northern Ireland, vitamin D production from solar UVB is lower due to both shorter vitamin D production seasons and lower peak UVB doses (Grant, 2008).

Table I New cancer in 14442 patients with basal cell carcinoma of the skin in Northern Ireland: 1993-2002 (all ages)

\begin{tabular}{|c|c|c|c|c|c|c|c|}
\hline \multirow[b]{2}{*}{ Site } & \multirow[b]{2}{*}{ ICD 10} & \multicolumn{2}{|c|}{ Cancer in men } & \multicolumn{2}{|c|}{ Cancer in women } & \multicolumn{2}{|c|}{ Cancer in men and women } \\
\hline & & $\mathbf{n}$ & SIR $(95 \% \mathrm{CI})$ & $n$ & SIR $(95 \% \mathrm{CI})$ & $n$ & $\operatorname{SIR}(95 \% \mathrm{CI})$ \\
\hline All & $\mathrm{C} 00-\mathrm{C} 97$ & 674 & I.I I $(1.03, I .19)^{*}$ & 530 & $1.07(0.98,1.17)$ & 1204 & $1.09(1.03,1.16)^{*}$ \\
\hline $\begin{array}{l}\text { All excluding } \\
\text { non-melanoma skin cancer }\end{array}$ & $\mathrm{C} 00-\mathrm{C} 97$ ex C44 & 460 & $1.01(0.92,1.10)$ & 391 & $1.08(0.97,1.19)$ & 851 & $1.04(0.97,1.11)$ \\
\hline Skin, melanoma & C43 & 19 & $2.68(1.47,3.88)^{*}$ & 19 & 2.1 I $(1.16,3.07)^{*}$ & 38 & $2.36(1.61,3.11)^{*}$ \\
\hline Skin, squamous cell & C44 & 214 & $1.27(1.10,1.44)^{*}$ & 139 & $0.99(0.83,1.15)$ & 353 & $1.14(1.02,1.26)^{*}$ \\
\hline Lung & $\mathrm{C} 33, \mathrm{C} 34$ & 101 & $1.13(0.91,1.36)$ & 51 & $1.19(0.86,1.51)$ & 152 & $1.15(0.97,1.33)$ \\
\hline Breast (female only) & C50 & & & 83 & $1.02(0.80,1.24)$ & & \\
\hline Cervix & C53 & & & 1 & & & \\
\hline Uterus & C54 & & & 19 & $1.52(0.84,2.21)$ & & \\
\hline Ovary & C56 & & & 10 & $0.61(0.23,1.00)$ & & \\
\hline Prostate & C6I & 107 & I. $17(0.95,1.39)$ & & & & \\
\hline Oesophagus and stomach & $\mathrm{Cl} 5, \mathrm{Cl} 6$ & 34 & $0.90(0.60,1.20)$ & 24 & $1.04(0.62,1.46)$ & 58 & $0.95(0.7|| .20)$, \\
\hline Oesophagus & $\mathrm{Cl} 5$ & 12 & $0.91(0.40,1.43)$ & 6 & $0.69(0.14,1.23)$ & 18 & $0.82(0.44,1.20)$ \\
\hline Stomach & $\mathrm{Cl} 6$ & 22 & $0.90(0.52,1.27)$ & 18 & $1.26(0.68,1.84)$ & 40 & $1.03(0.7|| .35)$, \\
\hline Colorectal & $\mathrm{Cl} 8-\mathrm{C} 21$ & 67 & $0.90(0.68,1.11)$ & 65 & $1.10(0.83,1.37)$ & 132 & $0.99(0.82,1.16)$ \\
\hline Colon & $\mathrm{C} 18$ & 44 & $0.92(0.65,1.19)$ & 41 & $0.99(0.69,1.30)$ & 85 & $0.95(0.75,1.15)$ \\
\hline Rectum & $\mathrm{C} 19-\mathrm{C} 21$ & 23 & $0.85(0.50,1.20)$ & 24 & $1.34(0.80,1.87)$ & 47 & $1.05(0.75,1.35)$ \\
\hline Haematological malignancies & $\mathrm{C} 81-\mathrm{C} 96$ & 45 & $1.24(0.88,1.60)$ & 29 & $1.01(0.64,1.38)$ & 74 & $1.14(0.88,1.40)$ \\
\hline Non-Hodgkin's lymphoma & $\mathrm{C} 82-\mathrm{C} 85$ & 19 & $1.30(0.72,1.89)$ & 17 & $1.20(0.63,1.77)$ & 36 & $1.25(0.84,1.66)$ \\
\hline Tobacco-related cancers & $\begin{array}{l}\mathrm{C} 00-\mathrm{Cl} 4, \mathrm{Cl}, \mathrm{Cl}, \mathrm{C} 22 \\
\mathrm{C} 25, \mathrm{C} 32, \mathrm{C} 33, \mathrm{C} 34, \mathrm{C} 53 \\
\mathrm{C} 64-\mathrm{C} 66, \mathrm{C} 67, \mathrm{C} 68, \mathrm{C} 92\end{array}$ & 193 & $0.95(0.81,1.08)$ & 113 & $1.02(0.83,1.21)$ & 306 & $0.97(0.86,1.08)$ \\
\hline
\end{tabular}

$\mathrm{Cl}=$ confidence interval; $\mathrm{SIR}=$ standardised incidence ratio. Bold values indicate $* P<0.05$. 
Table 2 New cancer in 640I patients with squamous cell carcinoma of the skin in Northern Ireland: 1993-2002 (all ages)

\begin{tabular}{|c|c|c|c|c|c|c|c|}
\hline \multirow[b]{2}{*}{ Site } & \multirow[b]{2}{*}{ ICD 10} & \multicolumn{2}{|c|}{ Cancer in men } & \multicolumn{2}{|c|}{ Cancer in women } & \multicolumn{2}{|c|}{ Cancer in men and women } \\
\hline & & $n$ & SIR (95\% CI) & $n$ & SIR $(95 \% \mathrm{CI})$ & $n$ & SIR $(95 \% \mathrm{CI})$ \\
\hline $\begin{array}{l}\text { All excluding non-melanoma } \\
\text { skin cancer }\end{array}$ & $\mathrm{C} 00-\mathrm{C} 97$ ex C44 & 352 & $1.34(1.20,1.48)^{*}$ & 174 & $1.21(1.03,1.39)^{*}$ & 526 & $1.29(1.18,1.40) *$ \\
\hline Skin, melanoma & $\mathrm{C} 43$ & 12 & $3.13(1.36,4.91)^{*}$ & 3 & $0.86(-0.11,1.82)$ & 15 & $2.04(1.01,3.08)^{*}$ \\
\hline Skin, basal cell & C44 & 197 & $1.97(1.69,2.25) *$ & 133 & $2.19(1.81,2.56) *$ & 330 & $2.05(1.83,2.27) *$ \\
\hline Cervix & C53 & & & 4 & $2.89(0.06,5.72)$ & & \\
\hline Uterus & C54 & & & 4 & $0.92(0.02,1.81)$ & & \\
\hline Ovary & C56 & & & 3 & $0.52(-0.07,|| 1)$. & & \\
\hline Prostate & C6I & 58 & I.01 $(0.75,1.27)$ & & & & \\
\hline Oesophagus and stomach & $\mathrm{Cl} 5, \mathrm{Cl} 6$ & 32 & $1.48(0.97,2.00)$ & 12 & $1.16(0.50,1.81)$ & 44 & $1.38(0.97,1.78)$ \\
\hline Oesophagus & $\mathrm{Cl} 5$ & 13 & $1.76(0.80,2.72)$ & 6 & $1.52(0.30,2.73)$ & 19 & $1.68(0.92,2.43)$ \\
\hline Stomach & $\mathrm{Cl} 6$ & 19 & $1.34(0.74,1.94)$ & 6 & $0.94(0.19,1.68)$ & 25 & $1.21(0.74,1.69)$ \\
\hline Tobacco-related cancers & $\begin{array}{l}\mathrm{C} 00-\mathrm{Cl} 4, \mathrm{Cl} \text {, } \mathrm{Cl} \text { 6, } \mathrm{C} 22 \\
\mathrm{C} 25, \mathrm{C} 32, \mathrm{C} 33, \mathrm{C} 34, \mathrm{C} 53 \\
\mathrm{C} 64-\mathrm{C} 66, \mathrm{C} 67, \mathrm{C} 68, \mathrm{C} 92\end{array}$ & 139 & $1.21(1.01,1.41)^{*}$ & 67 & $1.49(1.13,1.85)^{*}$ & 206 & $1.29(1.11,1.46)^{*}$ \\
\hline
\end{tabular}

$\mathrm{Cl}=$ confidence interval; $\mathrm{SIR}=$ standardised incidence ratio. Bold values indicate $* P<0.05$.

We found that SCC patients were at a high risk of subsequent melanoma, confirming the results of Wassberg et al (1999), who reported an almost three-fold increase in melanoma risk. This is most likely due to a shared phenotype and environmental risk factors, although patients with NMSC are more likely to be screened for melanoma, and thereby have a spuriously high melanoma rate.

Subsequent tobacco-related cancers were more likely in SCC patients and this is not a surprising finding as cigarette smoking has been associated with a two-fold increased risk of SCC (Grodstein et al, 1995).

In general, an association between skin cancer and a second primary cancer could reflect shared aetiologic factors or biased ascertainment of new primaries as a result of increased surveillance (Schottenberg 1996). It should also be noted that individuals who are at a high risk of skin cancer may have other risk-taking behaviours related to their increase in risk of a second primary cancer such as smoking, dietary intake and physical activity levels.

There are some limitations to our study. Although based on the past 10 years data, the mean period of follow-up was only 4 years primarily due to the advanced age of patients at diagnosis, especially within the SCC cohort. Our study concerns a predominantly white population and so is not generalisable to other racial, ethnic groups. A general limitation to this and other registry-based investigations is the lack of information about individual UV exposures and other hypothesised risk factors

Several strengths of our study include the availability of data by NMSC subtype and its inclusion of data on all pathologically confirmed NMSC in Northern Ireland. Loss to follow-up is likely to be low; data from the GRO (Northern Ireland) estimate that less than $0.1 \%$ of the population migrated from the province per year during the 1990s (NISRA, 2008). Population-based studies of BCC are rare as hospitalisation is not required, prognosis is favourable and it is not routinely registered in most cancer registries.

Our results show that patients with a BCC, SCC or melanoma, compared with the general population, have an increased risk of developing a new primary cancer, especially melanoma in men. Our findings may partly reflect risk factors in common between these tumours, such as UV exposure and smoking, but they do not agree with some earlier reports of a decreased risk of prostate cancer after skin cancer perhaps mediated through vitamin D production.

\section{REFERENCES}

Breslow NE, Day NE (1987) Statistical Methods in Cancer Research. Vol 2. The Analysis of Cohort Studies. International Agency for Research on Cancer: Lyon, 71. (IARC Scientific Publication no. 82

Davies T, Page M, Coebergh W (2007) ENCR Recommendations. Non-melanoma Skin Cancers, http://www.encr.com.fr/skinrecs.pdf (last accessed 28 August 2007)

De Vries E, Soerjomataram I, Houterman S, Louwman MW, Coeberg JW (2007) Decreased risk of prostate cancer after skin cancer diagnosis: a protective role of ultraviolet radiation? Am J Epidemiol 165: 966-972

Gorham ED, Garland CF, Garland FC, Grant WB, Mohr SB, Lipkin M, Newmark HL, Giovannucci E, Wei M, Holick MF (2007) Optimal vitamin D status for colorectal cancer prevention: a quantitative meta-analysis. Am J Prev Med 32: 210-216

Grant WB (2007) A meta-analysis of second skin cancers after a diagnosis of nonmelanoma skin cancer: additional evidence of that solar ultraviolet B irradiance reduces the risk of internal cancers. J Steroid Biochem Mol Biol 103: 668-674

Grant WB (2008) The effect of solar UVB doses and vitamin D production, skin cancer action spectra, and smoking in explaining links between skin cancers and solid tumours. Eur $J$ cancer 44: $12-15$

Grodstein F, Speizer FE, Hunter DJA (1995) A prospective study of incident squamous cell carcinoma of the skin in the nurses' health study. $J$ Natl Cancer Inst 87: 1061 - 1066

Hoey SE, Devereux CE, Murray L, Catney D, Gavin A, Kumar S, Donnelly D, Dolan OM (2007) Skin cancer trends in Northern Ireland and 
consequences for provision of dermatology services. $\mathrm{Br}$ J Dermatol 156(6): $1301-1307$

Jemal A, Devesa SS, Hartge P, Tucker MA (2001) Recent trends in cutaneous melanoma incidence among whites in the United States. J Natl Cancer Inst 93: 678-683

Northern Ireland Statistics and Research Agency (2008) Northern Ireland Migration Flows 1991-2007. Population statistics online, available from URL: http://www.nisra.gov.uk/

Schottenberg D (1996) Basal-cell carcinoma of the skin: a harbinger of cutaneous and noncutaneous multiple primary cancer. Ann Intern Med 125: $852-854$
Soerjomataram I, Louwman WJ, Lemmens VE, Coebergh JW, de Vries E (2008) Are patients with skin cancer at lower risk of developing colorectal or breast cancer? Am J Epidemiol 167: 1421 - 1429

Tuohimaa P, Pukkala E, Scélo G, Olsen JH, Brewster DH, Hemminki K, Tracey E, Weiderpass E, Kliewer EV, Pompe-Kirn V, McBride ML, Martos C et al (2007) Does solar exposure, as indicated by nonmelanoma skin cancers, protect from solid cancers: vitamin D as a possible explanation. Eur J Cancer 43: 1701 - 1712

Wassberg C, Thorn M, Yuen J, Ringborg U, Hakulinen T (1999) Second primary cancers in patients with squamous cell carcinoma of the skin: a population-based study in Sweden. Int J Cancer 80: 511-515 